\title{
Exploring the Relationships among Epistemological Beliefs, Nature of Science, and Conceptual Change in the Learning of Evolutionary Theory
}

\author{
Moon-Heum Cho • Deanna M. Lankford • \\ Daniel J. Wescott
}

Published online: 25 March 2011

(C) Springer Science+Business Media, LLC 2011

\begin{abstract}
We explored the relationship between epistemological beliefs and nature of science in a college biology course. One hundred thirty-three college students participated in the research. Exploratory factor analysis with 29 Nature of Science (NOS) items yielded three aspects of NOS: empirical, tentative, and sociocultural nature of scientific knowledge. Pearson $r$ correlations suggested that students who have immature epistemological beliefs are more likely to also have immature beliefs of nature of science. In addition, students' epistemological beliefs significantly correlate with their conceptual change but their beliefs about nature of science did not. The research is significant in that it provides empirical evidence explaining the relationship between students' epistemological beliefs and nature of science as well as the relationships between epistemological beliefs and conceptual change in evolution theory.
\end{abstract}

Keywords Epistemological beliefs - Nature of science . Conceptual change $\cdot$ Evolutionary theory $\cdot$ College students

\footnotetext{
M.-H. Cho

Kent State University-Stark,

North Canton, OH, USA

D. M. Lankford

University of Missouri,

Columbia, MO, USA

D. J. Wescott

Florida International University,

Miami, FL, USA

M.-H. Cho $(\bowtie)$

6000 Frank Ave. N.W.,

North Canton, OH 44729, USA

e-mail: mhcho@kent.edu
}

\section{Introduction}

Students often enter college biology courses with strongly held scientific misconceptions that interfere with their ability to understand accurate explanations. Therefore, one of the major goals in biology education is to help students engage in conceptual change; however, student conceptual change is difficult to accomplish, especially when students are learning about evolutionary theory (Bishop and Anderson 1990; Rutledge and Warden 2000). One of the common ways of teaching evolution theory is to discuss Darwin's voyage and the evidence he observed as integral to building the concept of evolution theory; however, often even well-designed lessons are not sufficient to help students undergo conceptual change. As a result, students often complete biology courses holding the same misconceptions they had prior to taking the course, even after numerous biology courses (Bishop and Anderson 1990).

Recently, researchers have begun to examine role of individuals' affective characteristics such as epistemological beliefs on ability of students to undergo conceptual change (Sahin 2010; Stathopoulou and Vosniadou 2007). Sahin (2010) discovered that the ability of students to understand physics concepts was significantly related to their beliefs about physics and physics learning. Likewise, Stathopoulou and Vosniadou (2007) found students' epistemological beliefs about physics was a strong predictor of their understanding of physics, and that commonly students' epistemological beliefs are related to conceptual understanding about science; however, few studies have been conducted in biology to investigate the relationships between epistemological beliefs and conceptual change. Because students' epistemological beliefs are domain specific, more research is necessary to understand the role 
of epistemological beliefs in biology - in particular, evolution theory.

Research on epistemological beliefs started from Perry's research (1970) and has continuously expanded its interests into diverse areas including learning strategies, motivation, and conceptual change. Despite of decades of research efforts, there is still lack of agreement among educators of different disciplines (e.g., educational psychologists and science researchers) when it comes to defining epistemological beliefs. Educational psychologists define epistemological beliefs as personal beliefs about knowledge and knowing (Hofer and Pintrich 1997; Shommer-Aikins 2004). Science educators, on the other hand, describe epistemological beliefs as the Nature of Science (NOS), which are context-specific beliefs about knowledge and knowing of science. The lack of interaction between the two disciplines may cause confusion to researchers or educators who are interested in the relationships between epistemological beliefs and conceptual change in science, and no research has been conducted to investigate the relationship between epistemological beliefs and conceptual change by using both disciplinary perspectives. Therefore, in this study, we explored for the first time the relationships among epistemological beliefs, nature of science, and conceptual change.

\section{Epistemological Beliefs from Educational Psychologists' Perspective}

Research on epistemological beliefs was initiated by Perry (1970). He found that students do have strong beliefs about knowing and knowledge but they can change over time. Perry (1970) argued that students entering college perceive knowledge to be simple, certain, and provided by the instructor; however, upon graduation, the same students often hold more sophisticated beliefs, viewing knowledge as complex, tentative, and derived from reason and observation.

Since Perry's research, perhaps one of the most influential studies in epistemological beliefs was conducted by Schommer (1990). Schommer suggested that students' epistemological beliefs consist of a collection of more or less orthogonal beliefs. She made the case that students' epistemological beliefs have diverse dimensions that are in a continuum from less to more sophisticated, and that the beliefs are developed from novice to sophisticated level. Schommer suggested five theoretical dimensions of epistemological beliefs: (1) the structure of knowledge (from simple to complex nature of knowledge), (2) the stability of knowledge (from factual to constantly changing nature of knowledge), (3) the source of knowledge (from omniscient source to empirically evidenced-based nature of knowledge), (4) the speed of learning (from quick to gradual nature of learning), and (5) the ability to learn (from fixed or innate to incremental nature of ability). Using exploratory factor analyses, Schommer found support for these dimensions of epistemological belief, with the exception of the source of knowledge (3). Although there are still ongoing debates about the dimensions of epistemological beliefs (Hofer and Pintrich 1997), Schommer's dimensions are commonly accepted among educational psychologists. In an attempt to more fully understand the dimensions of epistemological beliefs, Bendixen et al. (1998) extracted items from the research of Schommer and generated new items. They found five dimensions of epistemological beliefs that they identified as (1) certain knowledge, (2) simple knowledge, (3) omniscient authority, (4) quick learning, and (5) innate ability. Certain knowledge beliefs are held by students that view knowledge as certain or absolute rather than tentative. Students who have simple knowledge beliefs view knowledge as simple rather than contextual and contingent. Omniscient authority depicts knowledge as coming from "out of self," such as from textbook or teachers, rather than coming from interactions with others. Quick learning explains whether students view learning as occurring quickly rather than gradually, and innate ability describes intelligence or learning ability as innate and therefore effort does not make any difference.

\section{Nature of Science from Science Researchers' Perspective}

Nature of science is the common name used by science researchers to describe epistemological beliefs in science contexts. NOS addresses multiple issues related to the philosophical assumptions of science (Smith and Wenk 2006), including: values, development, conceptual inventions, development of consensus within the scientific community, and unique characteristics of scientific knowledge (Lederman 1992; Tsai 2007).

Perhaps the definition of NOS developed by Lederman (1992) is most widely used. Lederman (1992) defined the phrase "Nature of Science" as a way of knowing or the values and beliefs that are inherent to the development of scientific knowledge; however, there is a lack of consensus among philosophers, historians, and sociologists of science on what actually constitutes NOS (Abd-El-Khalick 2005; Abd-El-Khalick and Lederman 2000; Alters 1997; Clough and Olson 2008; Osborne et al. 2003). Osborne et al. (2003) cite research findings by Alters (1997) to provide an empirical basis for the lack of consensus about NOS. Alters (1997) surveyed 217 members of the U.S. Philosophy of Science Association, and his interpretation of the 187 responses indicated no single account of NOS existed among study participants. Science educators often reference NOS as a means of explaining what science is, how it works, and how scientists function (Clough and Olson 2008). 
Abd-El-Khalick (2005) reports science educators often have different conceptions of NOS and what should be presented to students.

There appears to be a level of generality, although not complete agreement, regarding certain aspects of NOS (AAAS 1993; Abd-El-Khalick 1998, 2005; NRC 1996; Smith et al. 1997). The general aspects of NOS are described as four aspects of science. These general aspects of NOS include perceptions of scientific knowledge as: (a) tentative and, as such, subject to change; (b) supported by, based upon, or derived from empirical evidence resulting from observations of the natural world; (c) described as theory-laden with explanations derived in part from human inference, imagination, and creativity; (d) influenced by social and cultural aspects of society (AAAS 1993; Abd-ElKhalick 1998, 2005; Lederman 1992; NRC 1996; Smith et al. 1997). Each of these four dimensions warrants further discussions.

Empirical Nature of Science The empirical nature of science refers to the manner in which new scientific knowledge is generated, validated, and accepted by the scientific community. Science is described as a way of knowing that demands evidence for validation and acceptance among members of the scientific community (AAAS 1993; Lederman 1992). Abd-El-Khalick (2005) posits scientific knowledge is generated through "critical, negotiated, and collaborative inquiries that are propelled by scientists' imaginations and bound only by their observations of the natural world" (p. 17). Hence, scientific knowledge is usually characterized as knowledge derived from or based upon observations of the natural world; as a result, science demands that claims are backed with evidence that can be confirmed through scientific inquiry and supported with logical argument (AAAS 1993; Abd-ElKhalick and Lederman 2000). Evidence to support scientific knowledge is filtered through scientists' perception of their observations and also through intricate instrumentation with data analysis and interpretation guided by elaborate theoretical frameworks. Therefore, science is unique compared to other ways of knowing because scientific knowledge is based upon empirical evidence filtered by human interpretation (Lederman 1992).

Scientific Theories and Laws Because science is a human endeavor, it is ultimately dependent upon individual or group interpretation and, therefore, described as theoryladen (Abd-El-Khalick and Lederman 2000). Making sense of observations of phenomena is accomplished through the development of explanations that are consistent with existing scientific knowledge and principles; such explanations are referenced as theories (AAAS 1993). Theories are overarching explanations of the natural world. Theories are typically inferred and explain the relationship between observations of multiple phenomena, most of which are not directly observable or testable (Lederman et al. 2002). An example would be the kinetic molecular theory. This theory explains that all matter is composed of small particles and describes the relationship between those particles within the context of solids, liquids, and gases. This theory can also explain rates of diffusion, chemical reactions as well as other phenomena related to changes in matter resulting from kinetic energy and energy transfer (Abd-El-Khalick et al. 2001). Laws, in contrast, are described by Lederman et al. (2002) as "descriptive statements of relationships among observable phenomena" (p. 500). Therefore, it is important to note that theories and laws are different types of knowledge and that theories do not become laws over time (Abd-El-Khalick et al. 2001). In summary, scientific theories offer strong evidence for explanations of phenomena never directly observed; theories are tentative and undergo elaboration and modification with new understanding of science (Wong and Hodson 2009).

Social and Cultural Embeddedness Science is a human effort; and, as such, it is influenced by the context of social and cultural views of scientists and the culture in which the research is conducted (Abd-El-Khalick and Lederman 2000; Lederman 1992; Lederman et al. 2002). Lederman et al. (2002) defined naïve views of the cultural influence upon the nature of science as the belief that science could not be influenced by culture or society and the more informed view as an understanding of the influence of societal and cultural factors upon the acceptance of scientific ideas.

Tentative Nature of Science Science is different from other ways of knowing because science relies upon observations of the natural world, demands supporting evidence, and encourages skepticism. Scientific knowledge, even though durable, is also tentative and subject to change within the context of new technologies and interpretations (Lederman et al. 2002). Popper (1963) posited that scientific hypotheses, theories, and laws can never be absolutely proven, regardless of the existence of supporting empirical evidence. Kuhn (1962) describes scientific revolutions as occurring when existing theories are no longer perceived to be satisfactory explanations and this dissatisfaction with existing theory drives scientific thinking and research, ultimately resulting in the formation of new theories. Wong and Hodson (2009) found that scientists subscribed to the belief that both theories and laws are subject to change as new knowledge of the phenomena is gained with the introduction and application of new technologies. Hence, scientific knowledge is far 
from absolute and will continually to be modified and elaborated upon as new understandings of phenomena are realized.

\section{Research Purpose}

The overarching purpose of this research was to investigate the relationship between college students' epistemological beliefs and their views on the nature of science. We also explored for the first time the relationships among epistemological beliefs, NOS, and conceptual change while learning about evolutionary theory. The questions that guided this study were:

- What are, if any, the relationships between epistemological beliefs and nature of science?

- What are, if any, the relationships between epistemological beliefs and conceptual change in evolutionary theory?

- What are the relationships between nature of science and conceptual change in the evolutionary theory?

\section{Method \\ Participants}

The research was conducted in an introduction to biological anthropology course throughout the consecutive semesters between 2006 and 2007 in a Midwestern university. The sophomore-level course fulfills the biological sciences general education requirement at the university, and most of the students enrolled are non-science majors. Furthermore, most of the study participants graduated from in-state high schools in which teaching evolution theory explicitly was not strongly encouraged. A total of 133 students participated in the study with 57 and 76 students in each semester participating in the study, respectively. Of the participants, $51.1 \%$ were female, $54.9 \%$ were either freshmen or sophomore, $75.2 \%$ of students were between 18 and 21 years old, and $60.2 \%$ of the students had not taken a college-level biology courses before taking this course.

\section{Measurements}

Three measurements were used for this research: Epistemological Beliefs Inventory (EBI) (Schraw et al. 1995), NOS, and Understanding Evolutionary Theory Survey.

Epistemological Belief Inventory EBI consists of 32 items and explains five dimensions of beliefs about knowledge and knowing: simple knowledge, certain knowledge, omniscient authority, quick learning, and fixed ability (Schraw et al. 1995). Among 32 items, simple knowledge beliefs were measured with seven items (e.g., "Too many theories just complicate things," or "The best ideas are often the most simple.") Certain knowledge beliefs were measured with eight items (e.g., "Truth means different things to different people," or "If two people are arguing about something, at least one of them must be wrong.") Omniscient authority beliefs were measured with five items (e.g., "People should always obey the law," or "People who question authority are troublemakers.") Quick learning beliefs were measured with five items (e.g., "Students who learn things quickly are the most successful," or "Working on a problem with no quick solution is a waste of time.") Fixed ability beliefs were measured with seven items (e.g., "Some people will never be smart no matter how hard they work," or "How well you do in school depends on how smart you are.")

A five-point Likert scale was used where 1 indicates "not at all true of me" and 5 indicates "very much true of me." Cronbach alpha was used to check reliability of EBI dimensions. With our samples, Cronbach alphas range from 0.42 to 0.65 where alpha values of simple knowledge, certain knowledge, omniscient authority, quick learning, and fixed ability are $0.63,0.51,0.65,0.42$, and 0.68 , respectively.

Nature of Science There are quite number of published quantitative instruments to measure students' beliefs about NOS (Lederman et al. 1998). Perhaps one of the most widely used instruments to measure NOS is Lederman and his colleague's Views of Nature of Science Questionnaire (VNOS; Lederman et al. 1998, 2002). VNOS has several evolved forms and the final form is VNOS-Form C. The final version of VNOS-Form C consists of ten open-ended questions, and each question is printed on a single page. According to Lederman et al.'s recommendation of using VNOS-Form $\mathrm{C}$, administrators are encouraged not to set time limits when the questionnaire is administered in a classroom. In addition, after the participation in the open-ended VNOS-Form C questions, a reasonable portion of correspondents (15-20\%) should be individually interviewed. Then, multiple researchers analyze both open-ended questions and interview data to establish interrater reliability for generated individuals' profiles of NOS. Although the VNOS proved its reliability and validity (Lederman et al. 2002), it has limitations for quantifying individuals' NOS profiles as well as for administering in a large classroom, especially, in this case, in a required general course for non-major students. Therefore, we decided to use existing measurements that align with our literature review as well as reflecting educators' perspectives on NOS. 
Through an extensive search, we found two surveys that meet our criteria. The two surveys include the 17item NOS survey used for American pre-service teachers in the College of Biology program based at Oregon State University. The survey can be viewed at the following web address: http://www.science.oregonstate.edu/bi10x/bi102/ portfolios/natureofsciencesurveyblank.doc. A second, 25item NOS survey was developed by Indiana State University's Evolution and the Nature of Science Institutes for American high school teachers to use in their classrooms and can be viewed at the following web address: http://www. indiana.edu/ ensiweb/lessons/sci.tst.html. Items in the two surveys were mainly used to create an item pool for NOS ( $n=29$; see Appendix A). Items in the both surveys were modified to correspond to our NOS literature. For this study, a 7-point Likert scale was used where 1 indicates "not at all true of me" and 7 indicates "very much true of me."

An Exploratory Factor Analysis was conducted to identify the latent variables of the new instrument with our participants in the study. The principle component analysis yielded 11 factors that explained $63.40 \%$ of the total sample variation. Promax rotation was used because underlying factors are related to some degree. After applying a cutoff value of 0.40 , three factors were retained that explain a total $29.96 \%$ of the variance. The three factors account for $15.85 \%, 7.38 \%$, and $6.74 \%$ of the variance, respectively. Table 1 shows the three factors characterized as: (a) empirical nature of scientific knowledge, (b) tentative nature of scientific knowledge, and (c) sociocultural nature of scientific knowledge, with Cronbach's coefficient alpha respectively of $0.69,0.59$, and 0.47 .

Understanding Evolutionary Theory Survey The authors of this study developed the Understanding Evolutionary Theory Survey for this study using previous conceptual change studies (Bishop and Anderson 1990; Greene 1990; Wescott and Cunningham 2005). The survey consists of 34 items, including 13 questions about natural selection, eight questions about adaptation, seven questions about general evolution theory, and six questions about mutation, variation, and inheritance. Students' answers were recorded with two options: true or false.

\section{Research Procedures}

The research was conducted ethically following the protocols approved by campus Institutional Review Board. At the beginning of the semester, the researchers visited the class and administered Epistemological Belief Inventory and Nature of Science survey. The Understanding Evolutionary Theory Survey was administered both at the beginning and at the end of the semester. The surveys were pen- and pencil-based, and students' participation in the research was voluntary.

Table 1 Factor structures of nature of science

Items

Factor loadings

F1 $\quad$ F2 $\quad$ F3

10. Scientific explanations are based on empirical observations or experiments

$\begin{array}{rrr}\mathbf{0 . 6 9} & 0.02 & -0.00 \\ \mathbf{0 . 6 4} & -0.01 & -0.06 \\ \mathbf{0 . 5 6} & -0.21 & -0.11 \\ & & \\ \mathbf{0 . 5 0} & 0.23 & -0.08 \\ \mathbf{0 . 4 4} & 0.04 & 0.24 \\ \mathbf{0 . 4 1} & -0.11 & 0.12 \\ -0.07 & \mathbf{0 . 7 7} & -0.05 \\ & & \\ 0.11 & \mathbf{0 . 5 9} & 0.05 \\ -0.13 & \mathbf{0 . 4 0} & -0.01 \\ -0.04 & 0.04 & \mathbf{0 . 6 6} \\ 0.02 & -0.07 & \mathbf{0 . 5 0}\end{array}$

2. Because science is based upon empirical evidence it is both testable and refutable

26. Science is different from other ways of knowing because science requires evidence, emphasizes the use of empirical standards, logical arguments, and skepticism

7. After scientists have developed a theory, the theory may change if new evidence is discovered to be valid

9. Scientific theories change with new ways of looking at old evidence

28. Science is a process of discovering and revealing things that we cannot see with our eyes

15. Scientists work together in the formulation of new scientific knowledge and rarely disagree about their ideas and explanations

18. Something that has been researched extensively and "proven scientifically" is no longer subject to change

21. Acceptance of new scientific knowledge is straightforward and involves minimal controversy

14. Scientific research can be influenced by the race, gender, nationality, or religion of the scientist

of

22. Scientists must utilize creativity and art in the development of new theories about the natural world

Unique factor loadings $>0.40$ are in bold. Analysis is based on 133 observations. Item scores range from 'not at all true of me' (1) to 'very much true of me' (7). Internal consistency estimates for factors 1,2 , and 3 are $0.69,0.59$, and 0.47 , respectively

Factor 1 empirical nature of scientific knowledge, factor 2 tentative nature of scientific knowledge, and factor 3 social cultural nature of scientific knowledge 


\section{Results}

Relationships Between Epistemological Beliefs and Nature of Science

Table 2 summarizes the descriptive statistics for epistemological beliefs and nature of science.

In order to find the relationships between EBI and NOS, a Pearson $r$ correlation was conducted (see Table 3). The results show moderate and significant relationships between epistemological beliefs and nature of science. First, simple knowledge beliefs negatively correlated with tentative NOS, $r(131)=-0.34, p<0.01$. This means the more students believe knowledge is simple, the less they are likely to believe the tentative nature of scientific knowledge. Second, certain knowledge beliefs negatively correlated with both tentative $(r(131)=-0.34)$ and sociocultural nature of scientific knowledge $(r(131)=-0.32)$. This means the more students believe knowledge is certain, the less they are likely to believe tentative and sociocultural nature of scientific knowledge. Third, quick learning is negatively associated with both empirical $(r(131)=-0.19)$ and tentative nature of scientific knowledge $(r(131)=-0.36)$. This implies that the more students believe learning is quick, the less they are likely to believe both empirical and tentative nature of scientific knowledge. Fourth, fixed ability is negatively associated with tentative nature of scientific knowledge $(r(131)=-0.22)$. This shows that the more students believe ability is fixed, the less they are likely to believe that scientific knowledge is tentative and may change with new findings, perceptions, or technologies. Last, omniscient authority is negatively related with both tentative $(r(131)=$ $-0.26)$ and sociocultural nature of scientific knowledge ( $r(131)=-0.19)$. This means the more students believe knowledge comes from authority (out of self) such as teacher, the less they are likely to believe in the tentative and sociocultural nature of scientific knowledge.

Table 2 Means and standard deviation for epistemological beliefs and nature of science

\begin{tabular}{lll}
\hline & M & SD \\
\hline Simple knowledge & 3.42 & 0.85 \\
Certain knowledge & 2.62 & 0.86 \\
Quick learning & 2.34 & 0.64 \\
Fixed ability & 3.56 & 0.90 \\
Omniscient authority & 3.59 & 0.99 \\
Empirical nature & 5.64 & 0.77 \\
Tentative nature & 5.97 & 0.86 \\
Sociocultural nature & 4.48 & 1.42 \\
\hline
\end{tabular}

Relationships Between Epistemological Beliefs and Conceptual Change

Among 133 students, 76 students participated in both the pre- and post-tests of Understanding Evolutionary Theory Survey. Among 76 students, 61.8\% were either freshmen or sophomores, $61.8 \%$ of the students were females, $80.3 \%$ of the students were between 18 and 21 years old, and $63.2 \%$ of the students had not taken a prior biology course. Among 76 students, 44 students' post-test scores were higher than the pre-test scores. Therefore, we interpreted that 44 students did change their misconceptions of evolution theory in some ways after the lessons; however, the degree of conceptual change (difference between pre-and post-test) varies from one to 15 . The differences between pre- and post-test results were used as dependent variables explaining conceptual change. Epistemological beliefs and nature of science were used separately as independent variables.

To investigate the relationships between epistemological beliefs and conceptual change in evolutionary theory, multiple regression analysis was conducted (see Table 4). The combination of five epistemological beliefs significantly predicted students' conceptual change $(F(5,70)=5.01$, $p<0.05)$ with two variables significantly negatively contributing to the prediction: fixed ability and omniscient authority. The beta weights suggested that two epistemological beliefs almost similarly predict conceptual change on evolution theory. This means the more students believe ability is fixed and knowledge comes from authority, the less likely they are to experience conceptual change. The adjusted $R$ squared value was 0.22 , indicating $22 \%$ of the variance in conceptual change on evolutionary theory was explained by the model.

\section{Relationships Between Nature of Science and Conceptual Change}

Table 5 shows the results of a multiple regression analysis conducted to investigate the relationships between NOS and conceptual change regarding evolutionary theory. The combination of three types of NOS beliefs did not significantly predict conceptual change $(F(3,72)=0.21, p>$ $0.05)$. The results show that students' beliefs about NOS do not explain conceptual change in evolution theory, at least with our samples.

\section{Discussion}

Our study shows that epistemological beliefs are associated with nature of science. The results suggest that immature epistemological beliefs are reflected as immature beliefs of nature of science or vice versa. In particular, all aspects of immature epistemological beliefs are negatively correlated 
Table 3 Intercorrelations for epistemological beliefs and nature of science

\begin{tabular}{|c|c|c|c|c|c|c|c|c|}
\hline & SK & CK & QL & FA & OA & EN & $\mathrm{TN}$ & SC \\
\hline SK & 1 & & & & & & & \\
\hline CK & $0.42 * *$ & 1 & & & & & & \\
\hline QL & $0.39 * *$ & $0.24 * *$ & 1 & & & & & \\
\hline FA & $0.22 *$ & 0.09 & $0.42 * *$ & 1 & & & & \\
\hline OA & $0.31 * *$ & $0.31 * *$ & 0.09 & 0.14 & 1 & & & \\
\hline $\mathrm{EN}$ & -0.07 & -0.10 & $-0.19^{*}$ & -0.15 & 0.04 & 1 & & \\
\hline $\mathrm{TN}$ & $-0.34 * *$ & $-0.34 * *$ & $-0.36^{* *}$ & $-0.22 *$ & $-0.26^{* *}$ & 0.16 & 1 & \\
\hline $\mathrm{SC}$ & -0.09 & $-0.32 * *$ & -0.05 & 0.06 & $-0.19^{*}$ & 0.09 & 0.12 & 1 \\
\hline
\end{tabular}

$S K$ simple knowledge, $C K$ certain knowledge, $Q L$ quick learning, $F A$ fixed ability, $O A$ omniscient authority, $E N$ empirical nature of scientific knowledge, $T N$ tentative nature of scientific knowledge, and $S C$ sociocultural nature of scientific knowledge

$* * p<0.01, * p<0.05$

with tentative nature of scientific knowledge. This shows tentative nature of scientific knowledge is a significant aspect of NOS and is aligned with all aspects of epistemological beliefs. In addition, certain knowledge and omniscient authority are negatively associated with sociocultural nature of scientific knowledge. This means students who believe knowledge is certain and comes from authority are not likely to recognize that scientific knowledge is influenced by social and cultural contexts. In addition, quick learning beliefs are negatively related with empirical nature of scientific knowledge. This demonstrates that students who believe learning is quick are less likely to recognize the empirical nature of scientific knowledge. All in all, the results consistently show that educators should help students develop both mature epistemological beliefs and familiarity with NOS because epistemological beliefs and NOS are interrelated.

The present study further investigated the role of epistemological beliefs and NOS on students' conceptual change in a college biology course. The two sets of multiple regression results indicated that students' beliefs about nature of science did not predict their conceptual change. Instead, students' beliefs about nature of knowledge and knowing significantly predicted their conceptual change regarding evolutionary theory. In particular, two variables (fixed ability and omniscient authority) significantly contributed to explaining the acquisition of scientific knowledge by the students. Thus, with our samples, the data suggest that students' beliefs about knowledge and knowing influence conceptual change more than beliefs about NOS.

Recently, Clough and Olson (Clough 2007; Clough and Olson 2008) raised concerns about teaching NOS tenets. For example, Clough (2007) is concerned that NOS tenets have become something to know rather than something to understand. Students in our research might have perceived that NOS was something to learn or know; therefore, students responded to the survey items as if they were responding to questions on a test rather than participating in a survey. We established this assumption from the fact that students' beliefs about NOS is high but beliefs about NOS did not predict conceptual change, which is different from the existing body of research (e.g., Sahin 2010; Stathopoulou and Vosniadou 2007). As Clough et al. suggested, nature of science is something to understand rather than something to know. Therefore, the study results suggest important implications for teaching epistemological beliefs and NOS in a college biology course.

Implications for Teaching Epistemological Beliefs and Nature of Science

Clough (2007) argued that posing questions is a valuable way to help students understand epistemological beliefs and NOS.

Table 4 Regression analysis for epistemological beliefs predicting conceptual change regarding evolutionary theory $(N=76)$

\begin{tabular}{|c|c|c|c|c|c|c|c|}
\hline Variable & $B$ & SE $B$ & $\beta$ & $\mathrm{t}$ & $R^{2}$ & $\operatorname{Adj} R^{2}$ & $F(5,70)$ \\
\hline 1. Certain knowledge & 1.13 & 0.64 & 0.22 & 1.77 & 0.28 & 0.22 & $5.01 *$ \\
\hline 2. Simple knowledge & -0.79 & 0.55 & -0.18 & -1.43 & & & \\
\hline 3. Quick learning & -1.33 & 0.81 & -0.21 & -1.64 & & & \\
\hline 2. Fixed ability & -1.12 & 0.48 & -0.28 & $-2.34 *$ & & & \\
\hline 3. Omniscient authority & -0.98 & 0.45 & -0.25 & $-2.16^{*}$ & & & \\
\hline
\end{tabular}

$* p<0.05$ 
Table 5 Regression analysis for nature of science predicting conceptual change regarding evolutionary theory $(N=76)$

$* p<0.05$

\begin{tabular}{llllllll}
\hline Variable & $B$ & SE $B$ & $\beta$ & $\mathrm{t}$ & $R^{2}$ & Adj $R^{2}$ & $F(3,72)$ \\
\hline 1. Empirical nature & 0.77 & 0.59 & 0.16 & 1.30 & 0.06 & 0.02 & 0.21 \\
2. Tentative nature & 0.41 & 0.56 & 0.09 & 0.72 & & & \\
3. Social cultural nature & 0.29 & 0.30 & 0.12 & 0.98 & & & \\
\hline
\end{tabular}

Viney (2007) posited interactive lessons that emphasize both epistemological beliefs and NOS for students may be useful in challenging students' misconceptions about epistemological beliefs and NOS. The two researchers' suggestions commonly emphasized students' active participation in scientific research.

We believe two important instructional strategies for engaging students in critical thinking and problem solving are the case study and problem-based learning (PBL) instructional strategies (Herried 2007; Hmelo-Silver 2004). These approaches are effective ways to actively engage students in learning as well as to improve students' epistemological beliefs and understanding of the nature of science (Conley et al. 2004; Herried 2007; Hmelo-Silver 2004; Sahin 2010). When challenged with problems embedded in case studies or problem scenarios, students experience the scientific process, including posing questions, developing hypotheses, designing investigations, gathering data, analyzing and interpreting data, drawing conclusions, and supporting claims with evidence (Conley et al. 2004; Herried 2007; Hmelo-Silver 2004; Sahin 2010). Experiencing the scientific process will promote students' understanding of epistemological beliefs and beliefs about NOS. For example, Conley et al. (2004) used hands-on and inquiry-oriented science instruction over nine weeks and found young students (fifth grade elementary school students) developed more sophisticated epistemological beliefs when pre- and post-test of epistemological beliefs were compared. The results imply that the case study and PBL approaches that use real data and situations have the potential to improve college students' epistemological beliefs and knowledge of NOS as well.

\section{Implications for Teaching Evolution Theory}

Evolution theory is a difficult concept to teach in a biology class because teachers fearing confrontation with students often avoid controversial concepts such as evolution (Nickels et al. 1996). Collegiate classes often treat evolution as a topic amid a plethora of topics taught throughout the semester rather than a unifying theme throughout the course (Farber 2003). Furthermore, entrylevel biology classes are typically very large and likely to consist of well over 100 students, making the implementation of case study or PBL instructional strategies difficult for instructors. Farber (2003) suggests implementing a historical case study approach, similar to a PBL approach, to engage students with an investigation focused on natural selection and evolution theory. The case study approach engages students in gathering evidence, assessing the credibility of evidence, formulating evidence-based explanations, and testing explanations against current scientific knowledge (Herried 2007; NAS 1998). Hence, scientific knowledge emerges from the intersection of human intelligence with data gathered through observation and experimentation; evolution is an example of this type of knowledge as well as an organizational theme in biology (NAS 1998).

\section{Appendix A}

Nature of Science Items

1. Scientific concepts and discoveries can stimulate new questions and sometimes new problems.

2. Because science is based upon empirical evidence it is both testable and refutable.

3. Different scientists may arrive at different solutions resulting from research investigations focused upon the same problem.

4. Science is mostly concerned with collecting facts about the natural world.

5. Scientific solutions cannot be based merely upon personal opinion, belief, or judgment.

6. Human imagination cannot be involved in the creation of new scientific knowledge.

7. After scientists have developed a theory, the theory may change if new evidence is discovered to be valid.

8. Disagreement between scientists is considered to be one of the weaknesses of science.

9. Scientific theories change with new ways of looking at old evidence.

10. Scientific explanations are based on empirical observations or experiments.

11. Scientists always provide tentative answers to questions.

12. Because scientific knowledge has been developed through empirically based research it is considered to be a highly reliable form of knowledge.

13. A scientific theory is not supported by as much scientific evidence as a law of science.

14. Scientific research can be influenced by the race, gender, nationality, or religion of the scientist. 
15. Scientists work together in the formulation of new scientific knowledge and rarely disagree about their ideas and explanations.

16. Requiring evidence to support claims is important in science and in everyday life as well.

17. Science is never truth or facts because truth or facts can mean different things to different people.

18. Something that has been researched extensively and "proven scientifically" is no longer subject to change.

19. Scientists often try to disprove their own ideas.

20. Scientific explanations must be essentially disprovable.

21. Acceptance of new scientific knowledge is straightforward and involves minimal controversy.

22. Scientists must utilize creativity and art in the development of new theories about the natural world.

23. If a theory is continually tested and determined to be valid, it will become a law.

24. Theories are immature or unproven laws.

25. Scientists can be biased about what they want to believe rather than by what observations they make during their research.

26. Science is different from other ways of knowing and from other bodies of knowledge because science requires evidence, emphasizes the use of empirical standards, logical arguments, and skepticism.

27. Science is a means of identifying and collecting facts to enhance understanding about the natural world.

28. Science is a process of discovering and revealing things that we cannot see with our eyes.

29. Skepticism is important for scientists and for the general public.

\section{References}

Abd-El-Khalick, F. The influence of history of science courses on students' conceptions of the nature of science. Unpublished doctoral dissertation. Oregon State University, Oregon; 1998.

Abd-El-Khalick F. Developing deeper understandings of nature of science: the impact of a philosophy of science course on preservice science teachers' views and instructional planning. Int J Sci Educ. 2005;27(1):15-42.

Abd-El-Khalick F, Lederman NG. The influence of history courses on students' views of nature of science. J Res Sci Teach. 2000;37 (10):1057-95.

Abd-El-Khalick F, Lederman NG, Bell RL, Schwartz RS. Views of nature of science questionnaire (VNOS): Toward valid and meaningful assessment of learners' conceptions of nature of science. In proceedings of the annual meeting of The Association for the Education of Teachers of Science, Costa Mesa, CA: January $18-21,2001$.

Alters BJ. Whose nature of science? J Res Sci Teach. 1997;34(1):39-55.

American Association for the Advancement of Science. Benchmarks for science literacy. New York: Oxford University Press; 1993.
Bendixen LD, Schraw G, Dunkle ME. Epistemological beliefs and moral reasoning. J Psychol. 1998;132:187-200.

Bishop BA, Anderson CW. Student conceptions of natural selection and its role in evolution. J Res Sci Teach. 1990;27:415-27.

Clough MP. Teaching the nature of science to secondary and postsecondary students: questions rather than tenets. The Pantaneto Forum. Available from: http://www.pantaneto.co.uk/issue25/ clough.htm; 2007.

Clough MP, Olson JK. Teaching and assessing the nature of science: an introduction. Sci Educ. 2008;17:143-5.

Conley AM, Pintrich PR, Vekiri I, Harrison D. Changes in epistemological beliefs in elementary science students. Cont Educ Psyc. 2004;29:186-204.

Farber P. Teaching evolution and the nature of science. Am Biol Teach. 2003;65:347-54.

Greene ED. The logic of university students' misunderstanding of natural selection. J Res Sci Teach. 1990;27:875-85.

Herried CF. Start with a story: the case study method of teaching college science. Arlington: NSTA Press; 2007.

Hmelo-Silver CE. Problem-based learning: what and how do students learn? Educ Psychol Rev. 2004;16(3):235-66.

Hofer BK, Pintrich PR. The development of epistemological theories: beliefs about knowledge and their relation to learning. Rev Educ Res. 1997;67:88-140.

Kuhn TS. The structure of scientific revolutions. Chicago: University of Chicago Press; 1962.

Lederman NG. Students' and teachers' conceptions of the nature of science: a review of the research. J Res Sci Teach. 1992;29:33159.

Lederman NG, Wade PD, Bell RL. Assessing the nature of science: what is the nature of our assessment? Sci Educ. 1998;7:595-615.

Lederman NG, Abd-El-Khalick F, Bell R, Schwartz RS. Views of nature of science questionnaire: toward valid and meaningful assessment of learners' conceptions of nature of science. J Res Sci Teach. 2002;39:497-521.

National Academy of Science. Teaching about evolution and the nature of science. Washington, D.C: National Academy Press; 1998.

National Research Council. National science education standards. Washington DC: National Academic Press; 1996.

Nickels MK, Nelson CE, Beard J. Better biology teaching by emphasizing evolution and the nature of science. Am Biol Teach. 1996;58(6):332-6.

Osborne J, Collins S, Ratcliff M, Millar R, Duschl R. What "ideas about science" should be taught in school science? A Delphi study of the expert community. J Res Sci Teach. 2003;40:692-720.

Perry WG. Forms of intellectual and ethical development in the college years: a scheme. New York: Holt, Rinehart, and Winston; 1970.

Popper KR. Conjectures and refutations: the growth of scientific knowledge. London: Routledge; 1963.

Rutledge ML, Warden MA. Evolutionary theory, the nature of science, and high school biology teachers: critical relationships. Am Biol Teach. 2000;62(1):23-31.

Sahin M. Effects of problem-based learning on university students' epistemological beliefs about physics and physics learning and conceptual understanding of Newtonian mechanics. J Sci Educ Technol. 2010;19(3):266-75.

Schommer M. Effects of belief about the nature of knowledge on comprehension. J Educ Psychol. 1990;82:498-504.

Schraw G, Dunkle ME, Bendixen LD. Cognitive processes in welldefined and ill-defined problem solving. Appl Cogn Psychol. 1995;9:1-16.

Shommer-Aikins M. Explaining the epistemological belief system: introducing the embedded systemic model and coordinated research approach. Educ Psychol. 2004;39:19-29. 
Smith C, Wenk L. Relations among three aspects of first-year college students' epistemologies of science. J Res Sci Teach. 2006;43 (8):747-85.

Smith MU, Lederman NG, Bell RL, McComas WF, Clough MP. How great is the disagreement about the nature of science: a response to Alters. J Res Sci Teach. 1997;34(10):1101-4.

Stathopoulou C, Vosniadou S. Exploring the relationship between physics-related epistemological beliefs and physics understanding. Cont Educ Psychol. 2007;32:255-81.
Tsai C. Teachers' scientific epistemological views: the coherence with instruction and students' views. Sci Educ. 2007;91:222-43.

Viney M. Epistemology and the nature of science: a classroom strategy. Am Biol Teach. 2007;69(9):525-30.

Wescott DJ, Cunningham DL. Recognizing student misconceptions about science and evolution. MountainRise. 2005;2:1-8.

Wong SL, Hodson D. From the horse's mouth: what scientists say about scientific investigation and scientific knowledge. Sci Educ. 2009;93:109-30. 